\title{
Hydraulic Conductivity Variation of Coarse-Fine Soil Mixture upon Mixing Ratio
}

\author{
Choong-Ki Chung, ${ }^{1}$ Joon-Hyoun Kim, ${ }^{2}$ Joonyoung Kim, ${ }^{3}$ and Taesik Kim $\mathbb{D}^{4}$ \\ ${ }^{1}$ Department of Civil and Environmental Engineering, Seoul National University, Seoul 08826, Republic of Korea \\ ${ }^{2}$ The Board of Audit and Inspection of the Republic of Korea, Seoul 03050, Republic of Korea \\ ${ }^{3}$ Korea Railroad Research Institute, Uiwang-si, Gyeonggi-do 16105, Republic of Korea \\ ${ }^{4}$ Department of Civil Engineering, Hongik University, Seoul 04066, Republic of Korea \\ Correspondence should be addressed to Taesik Kim; taesik.kim@hongik.ac.kr
}

Received 7 August 2017; Revised 15 November 2017; Accepted 2 January 2018; Published 22 March 2018

Academic Editor: Kirk Hatfield

Copyright $\odot 2018$ Choong-Ki Chung et al. This is an open access article distributed under the Creative Commons Attribution License, which permits unrestricted use, distribution, and reproduction in any medium, provided the original work is properly cited.

\begin{abstract}
This paper presents the theoretical and experimental investigations of the hydraulic conductivity variation of the soil mixture that contains two distinct particle size distributions, coarse and fine soils. A new model for the hydraulic conductivity is introduced that focuses on the relationship between the coarse-fine soil mixing ratio and the hydraulic conductivity of the mixture. For the model verification, permeability tests were conducted. The glass beads and quality-controlled standard sand and soils obtained from fields were used for the specimen. The experiment results showed that the hydraulic conductivity of the soil mixture strongly depends on the mixing ratio. As the amount of the coarse soil contained in the fine soil increased, the hydraulic conductivity of the mixture decreased from that for the fine soil until the critical mixing ratio. This ratio is defined as the fine soils perfectly fill the voids between the coarse soils without remains. When the ratio is greater than the critical mixing ratio, the hydraulic conductivity is drastically increased with the mixing ratio up to that of the coarse soil. The comparison between the computed values and the test results shows that the introduced model successfully describes the measurements.
\end{abstract}

\section{Introduction}

The hydraulic conductivity of soil is important in geotechnical projects related to the determination of seepage, stability analyses, and settlement prediction. Many researchers have found that the hydraulic conductivity of soil is affected by many factors such as density, water contents, degree of saturation, void ratio, grain size distribution, and particle structure. Some examples are Hazen [1], Kozeny [2], Carman [3, 4], Burmister [5], Lambe [6], Olson [7], Mitchell et al. [8], Horn [9], Garcia-Bengochea et al. [10], Hauser [11], and Wang and Huang [12], to name a few.

A frequently cited theoretical model was suggested by Kozeny [2] and Carman [3, 4]. Kozeny [2] developed the model using analogy to pipe flow and flow in capillaries. Carman $[3,4]$ verified the Kozeny equation. He considered the water move around irregularly shaped particles, introduced the hydraulic radius concept, and used the wetted surface area per unit volume of particles, $S_{0}$. The KozenyCarman equation has taken several forms including the following one:

$$
k=C_{s}\left(\frac{\gamma_{w}}{\mu}\right) S R^{2} n,
$$

where $k$ is the hydraulic conductivity, $C_{s}$ is a coefficient of the shape and tortuosity of channels, $\mu$ is the viscosity, $\gamma_{w}$ is the density of water, $S$ is the degree of saturation, $R$ is the hydraulic radius, and $n$ is the porosity. The hydraulic radius can be computed by

$$
R=\frac{V_{w}}{V_{s} S_{0}}=\frac{e V_{s} S}{V_{s} S_{0}}=\frac{e S}{S_{0}},
$$

where $V_{w}$ is the volume of water, $V_{s}$ is the volume of solid, and $e$ is the void ratio. As noted by Chapuis and Aubertin [13], the Kozeny-Carman equation is not frequently used in practice due to the difficulty in determination of $S_{0}$. Several 
methods can be used to measure the specific surface of the soil particles to evaluate $S_{0}$ but they are not commonly used in soil mechanics and hydrogeology [13]. Freeze and Cherry [14] present the Kozeny-Carman equation with $d_{m}$ instead of $S_{0}$ in (2). This $d_{m}$ is called a representative grain size without any indication of how to calculate this equivalent diameter.

In the various models, the tortuosity is considered as an important factor. The tortuosity is used to describe the difference between the actual distance traveled by fluids and the macroscopic travel distance, owing to the sinuosity and interconnectivity of pore spaces $[4,15,16]$. In general, tortuosity depends on various factors including the shape, size, type of grains, pores, and grain size distribution [16]. Accordingly, there is ambiguity associated with the derivation of the actual distance traveled by fluids [17]. Many researchers have made an effort to find a simple relationship between the tortuosity and the porosity [18-22]. Among the proposed relations describing the relationship tortuosity $(\tau)$ versus $n, \tau=n^{-m}$ is the most frequently used, where $m$ is a value in the range of approximately 0.4 to 0.5 [19].

Experimental and empirical methods have also been employed to make the better prediction [1, 23-25]. Considering the relationships between the grain size and the hydraulic conductivity, Hazen [1] reported that the hydraulic conductivity of granular soils with uniform particles is proportional to the square of the effective particle size, $D_{10}$ [1]. Burmister [5] reported that the range of the grain size, shape of the gradation curve, and $D_{10}$ should be considered. Chen et al. [26] found that the hydraulic conductivity is strongly related to the median diameter $D_{50}$. Boadu [27] proposed the multivariate regression model to overcome the difficulty in the previous models. However, if soils are artificially mixed and compacted with selected particle sizes, those conductivity models for natural soils composed with various particle sizes are limited.

In practice, the binary mixtures such as compacted sandclay mixtures are often used as blankets or liners to form seepage barriers against fluids, including leachates from disposal facilities [28]. In this type of binary mixture, fine soils provide impermeability and coarse soils provide constructability, compaction efficiency, and better deformation control. The characteristics of binary granular mixtures were investigated by many researchers [29-34]. Fragaszy et al. [29] proposed a theoretical method to evaluate the effects of oversized particles in the clean granular soils, but they emphasized the effects on the density of soil mixture rather than on the hydraulic conductivity. Shakoor and Cook [30] compacted mixtures of poorly plastic soils with gravel by varying percentages of gravel. They found that the hydraulic conductivity was slightly increased when the gravel percentage was less than $50 \%$ and a significant increase for higher percentages. Marion [31] also found that the effects of the fraction of fine-grained soils on the hydraulic conductivity of the soil mixtures were complex based on the measured permeability of the soil mixture. Shelley and Daniel [32] investigated the influence of the percentage of gravel on the hydraulic conductivity of kaolinite and of mine spoil. They found that the hydraulic conductivity increased significantly with percentages of gravel higher than $60 \%$. Koltermann and Gorelick [33] proposed the hydraulic conductivity model for the binary granular mixture. They modified the ideal packing model concept by introducing a weighting coefficient that reflects the relative proportions of coarse and fine packing. Kamann et al. [34] proposed the hydraulic conductivity model for poorly sorted sands and gravely sands by expanding the model proposed by Koltermann and Gorelick [33].

The objective of this paper is to introduce a new simple model that describes the variations of hydraulic conductivity and dry density of the binary soil mixture that contains two distinct particle sizes, coarse and fine soils. Note that coarse and fine soils are defined by their relative particle sizes in the mixture. For example, sand is regarded as the fine soil in the gravel-sand mixture but is regarded as the coarse soil in the sand-silt mixture. The hydraulic conductivity variation is theoretically analyzed with respect to the coarse soil mixing ratio. The permeability test results are presented for the model verification. The mixtures of glass beads-Joomunjin sand, Joomunjin sand-kaolinite, and Gwanak granite soilSongdo silty clay were used for the model verification tests.

Existing models use many variables to estimate the hydraulic conductivity such as void ratio, particle size distribution, temperature, chemical components of soil, and viscosity of fluid. The introduced model herein focuses on the relationship between the mixing ratio and the hydraulic conductivity of the mixture, so the mixing ratio is the only variable. The average porosity and the hydraulic conductivities of the pure coarse soil and pure fine soil are used as given parameters.

\section{Two-Particle Model for Hydraulic Conductivity}

Fluid flow through soils finer than coarse gravel is laminar, and the hydraulic conductivity equations were derived from Poiseuille's law for flow through a round capillary [35]. Based on this, the starting point for the new derivation is the KozenyCarman equation (1), and this can be simplified as follows:

$$
k=A n^{*}
$$

where $A$ is a constant defined as $A=C_{s}\left(\gamma_{w} / \mu\right) S$ and the converted porosity $n^{*}$ for the hydraulic conductivity prediction is defined as $n^{*}=R^{2} n$.

Figure 1 shows three possible cases when the two different particle size soils are mixed. Note that the subscripts $c$ and $f$ indicate the index for the pure coarse soil and the pure fine soil, respectively. For example, the model parameters $n_{c}$ and $n_{f}$ are the porosities of the pure coarse soil and the pure fine soil, respectively. The hydraulic conductivities of $k_{c}$ and $k_{f}$ are expressed as

$$
\begin{aligned}
& k_{c}=A R_{c}^{2} n_{c}=A n_{c}^{*}, \\
& k_{f}=A R_{f}^{2} n_{f}=A n_{f}^{*} .
\end{aligned}
$$

For the sake of simplicity, the void ratios of the unmixed soil, $e_{0}$, are assumed to be the same (i.e., $e_{c}=e_{f}=e_{0}$ ), and the average value is employed for the model derivation. 


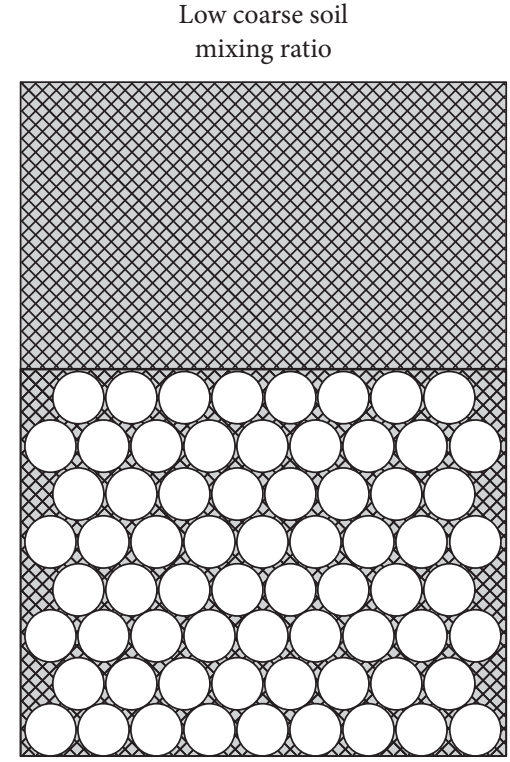

(a)
Critical mixing ratio

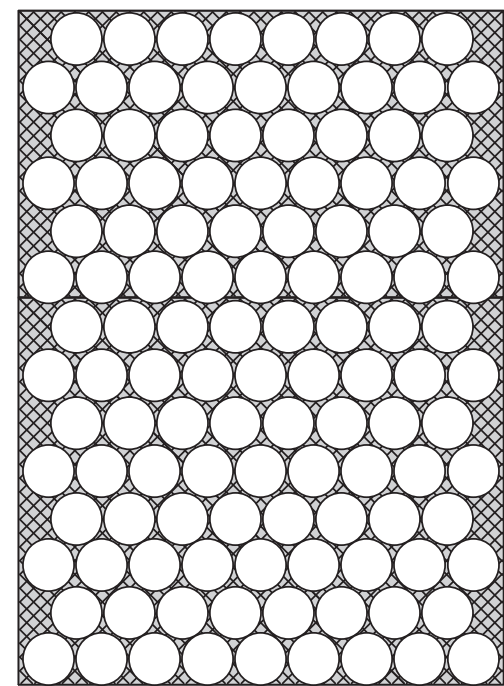

(b)

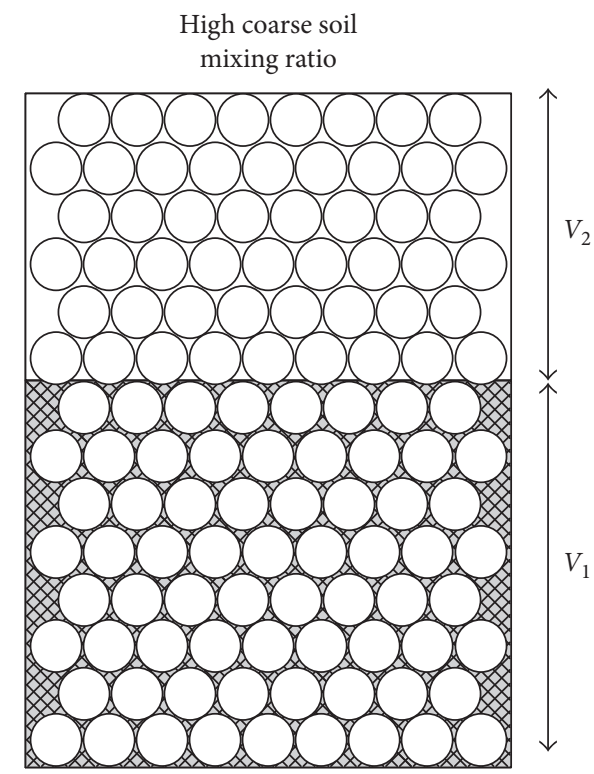

(c)

FIgURE 1: Particle arrangement condition with coarse and fine soil mixing ratios: (a) low mixing ratio of coarse soil; (b) critical mixing ratio; (c) high mixing ratio of coarse soil.

Accordingly, $n_{c}$ and $n_{f}$ are also assumed to be identical, and their average value is employed. The specific gravities of the unmixed soils are also presumed to be identical. The limitation caused by these assumptions will be discussed during the model verification. Although the porosities of the unmixed soils are assumed to be the same, $k_{c}$ is greater than $k_{f}$, owing to that the water conveyance area of the coarse soil is greater than that of the fine soil. To simplify the relationship more, the hydraulic conductivity correction factor $\alpha$ is employed and is defined as

$$
\alpha=\frac{k_{c}}{k_{f}}=\frac{A R_{c}^{2} n_{c}}{A R_{f}^{2} n_{f}}=\frac{A n_{c}^{*}}{A n_{f}^{*}}=\frac{R_{c}^{2}}{R_{f}^{2}} .
$$

Note that $k_{c}$ and $k_{f}$ are the given parameters for this suggested model, so the correction factor $\alpha$ is also known. In the following sections, the hydraulic conductivity of the soil mixture will be expressed with $\alpha$ and the coarse soil mixing ratio, $x$.

2.1. Converted Porosity for Low Coarse Soil Mixing Ratio. The weight ratio of coarse soil to fine soil can be expressed as

Weight of coarse soil : weight of fine soil $=x:(1-x)$. 
The weight fraction of each soil is given by the following equation using the void ratio, specific gravity, and volume

$$
\begin{aligned}
x & =\frac{G_{s c} \gamma_{w}}{1+e_{c}} V_{1} \quad<\text { coarse soil }>, \\
1-x & =\frac{G_{s f} \gamma_{w}}{1+e_{f}} \cdot \frac{e_{c}}{1+e_{c}} V_{1}+\frac{G_{s f} \gamma_{w}}{1+e_{f}} V_{2} \quad<\text { fine soil }>,
\end{aligned}
$$

where $G_{s}$ is the specific gravity of the soils, $e$ is the void ratio, $\gamma_{w}$ is the density of water, and $V_{1}$ and $V_{2}$ are the volumes shown in Figure 1. As previously noted, the subscripts $c$ and $f$ indicate the index for the pure coarse soil and the pure fine soil, respectively. Recall that for the sake of simplicity, the average void ratio of the unmixed coarse soil and the unmixed fine soil, $e_{0}$, is used, and the average specific gravity of the two soils, $G_{s}$, is taken. By solving (7) and (8) with respect to the volume, $V_{1}$ and $V_{2}$ are expressed as

$$
\begin{aligned}
& V_{1}=\frac{\left(1+e_{0}\right)}{G_{s} \gamma_{w}} x, \\
& V_{2}=\frac{(1-x)\left(1+e_{0}\right)-e_{0} x}{G_{s} \gamma_{w}} .
\end{aligned}
$$

Hence, the porosity of the soil mixture $n_{\text {mix }}$ is

$$
n_{\text {mix }}=\frac{\left(e_{0} / 1+e_{0}\right)^{2} V_{1}+\left(e_{0} / 1+e_{0}\right) V_{2}}{V_{1}+V_{2}} .
$$

As shown in Figure 1(a), the voids between the coarse soil particles are filled up with the fine soil. Hence, the water conveyance area in $V_{1}$ is governed only by the fine soil, so the hydraulic radius is not a variable but a constant equal to $R_{f}$. Therefore, for the low coarse soil mixing ratio, $n_{\text {mix }}$ is the only variable in determination of the hydraulic conductivity of the soil mixture. By plugging (9) and (10) into (11), the following equation is obtained:

$$
n_{\text {mix }}=\frac{e_{0}(x-1)}{e_{0} x-e_{0}-1} .
$$

Hence, the converted porosity can be obtained from the following equation:

$$
n_{\text {mix }}^{*}=R_{f}^{2} n_{\text {mix }}=R_{f}^{2} \frac{e_{0}(x-1)}{e_{0} x-e_{0}-1} .
$$

2.2. Converted Porosity at the Critical Mixing Ratio. In this paper, the critical mixing ratio is defined as the fine soil perfectly fills the void between the coarse soil particles without remains, as shown in Figure 1(b). In this case, $V_{2}$ is unable to discriminate from $V_{1}$ and the water conveyance area is governed by the fine soils, so the porosity is expressed as

$$
n_{\text {mix }}=\left(\frac{e_{0}}{1+e_{0}}\right)^{2}
$$

The converted porosity can be evaluated as

$$
n_{\text {mix }}^{*}=R_{f}^{2}\left(\frac{e_{0}}{1+e_{0}}\right)^{2} .
$$

The critical mixing ratio can be obtained by computing the ratio that makes (10) equal to zero. Hence, the weight fraction of the coarse soil at the critical mixing ratio, $x_{\mathrm{cr}}$, is

$$
x_{\mathrm{cr}}=\frac{e_{0}+1}{2 e_{0}+1} \text {. }
$$

2.3. Converted Porosity for High Coarse Soil Mixing Ratio. When the weight fraction of the coarse soil is high as shown in Figure 1(c), the voids in $V_{2}$ are not filled up with the fine soil. In this case, the weight fraction of each soil is

$$
\begin{aligned}
x=\frac{G_{s} \gamma_{w}}{1+e_{0}}\left(V_{1}+V_{2}\right) & \quad<\text { coarse soil }>, \\
1-x=\frac{G_{s} \gamma_{w}}{1+e_{0}} \frac{e_{0}}{1+e_{0}} V_{1} \quad & <\text { fine soil }>.
\end{aligned}
$$

By solving (17) and (18) with respect to the volume, $V_{1}$ and $V_{2}$ are expressed as

$$
\begin{aligned}
& V_{1}=\frac{(1-x)\left(1+e_{0}\right)^{2}}{e_{0} G_{s} \gamma_{w}}, \\
& V_{2}=\frac{\left(1+e_{0}\right)\left\{\left(2 e_{0}+1\right) x-\left(e_{0}+1\right)\right\}}{e_{0} G_{s} \gamma_{w}} .
\end{aligned}
$$

The porosity of the soil mixture $n_{\text {mix }}$ is the same as (11) and can be simplified as follows:

$$
n_{\text {mix }}=\frac{\left(e_{0}+1\right) x-1}{\left(e_{0}+1\right) x} .
$$

The water conveyance area in $V_{2}$ would be the same as that of the unmixed coarse soil. Accordingly, the hydraulic conductivity in $V_{2}$ should be the same as that of the unmixed coarse soil, $k_{c}$. To consider this, the correction factor $\alpha$ is employed as expressed in (5). The converted porosity for the hydraulic conductivity of the soil mixture is

$$
n_{\text {mix }}^{*}=R_{f}^{2} \frac{\left(e_{0} / 1+e_{0}\right)^{2} V_{1}+\alpha\left(e_{0} / 1+e_{0}\right) V_{2}}{V_{1}+V_{2}} .
$$

By plugging (19) and (20) into (22), the converted porosity for the hydraulic conductivity prediction is

$$
n_{\text {mix }}^{*}=R_{f}^{2} \frac{\left\{e_{0}(2 \alpha-1)+\alpha\right\} x-e_{0}(\alpha-1)-\alpha}{\left(e_{0}+1\right) x} .
$$

2.4. Hydraulic Conductivity and Dry Density Variation with the Mixing Ratio. The hydraulic conductivity of the soil mixture, $k_{\text {mix }}$, can be evaluated by (3). As previously noted, the aim of the introduced model herein is to describe the hydraulic conductivity variation with the mixing ratio when $k_{c}$ and $k_{f}$ are given. Hence, the only variable of the model is the weight fraction of the coarse soil, that is, the coarse soil mixing ratio $x$. The $k_{\text {mix }}$ is a piecewise function depending on the mixing ratio, and it is expressed as 


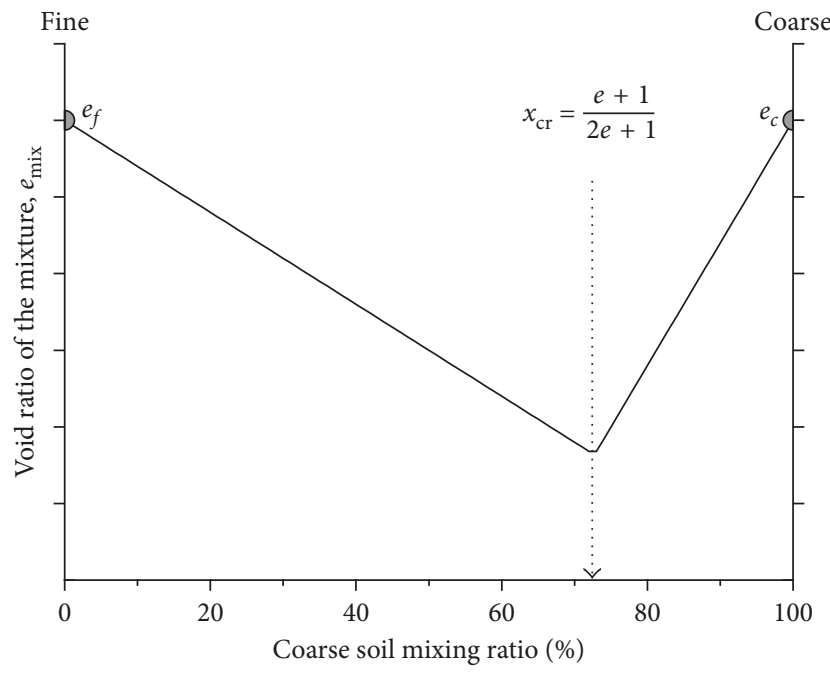

(a)

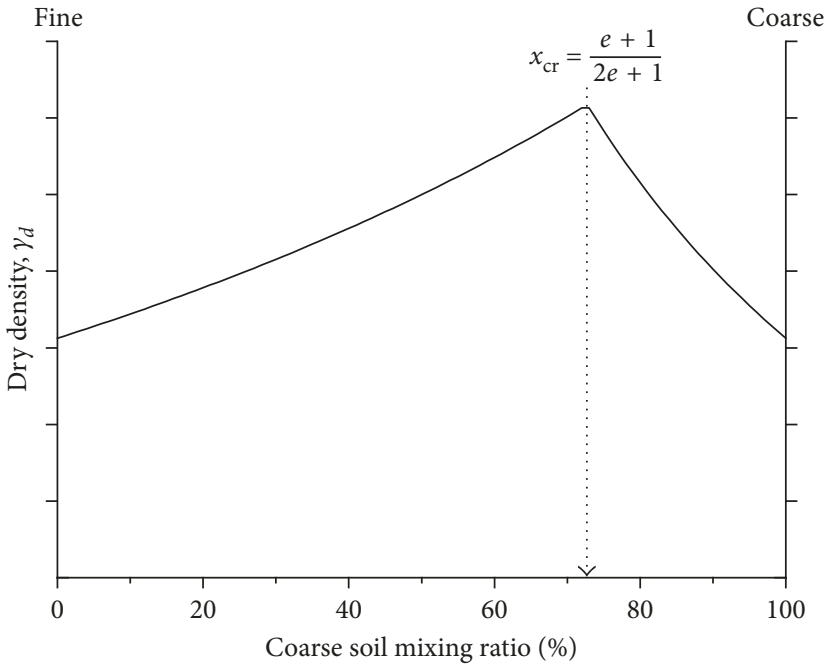

(b)

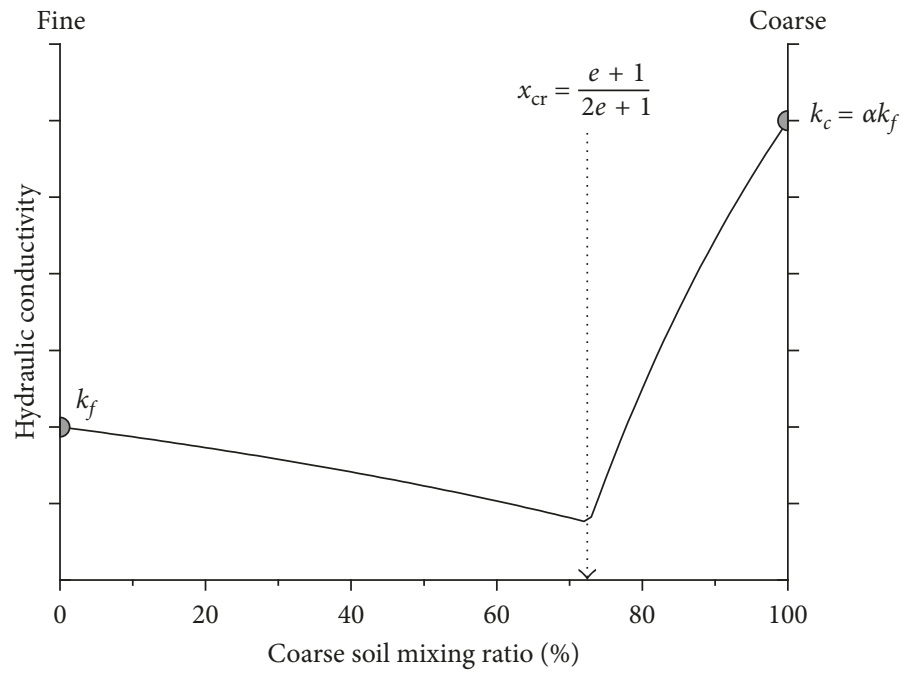

(c)

Figure 2: Prediction value variation with coarse soil mixing ratio: (a) void ratio variation; (b) dry density variation; (c) hydraulic conductivity variation.

$$
\begin{aligned}
& k_{\text {mix }}=A n_{\text {mix }}^{*}=A R_{f}^{2} \frac{e_{0}(x-1)}{e_{0} x-e_{0}-1} \text { if } x<x_{\mathrm{cr}}, \\
& k_{\text {mix }}=A R_{f}^{2} \frac{\left\{e_{0}(2 \alpha-1)+\alpha\right\} x-e_{0}(\alpha-1)-\alpha}{\left(e_{0}+1\right) x} \text { if } x \geq x_{\mathrm{cr}},
\end{aligned}
$$

where $A R_{f}^{2}$ can be evaluated from either $k_{c}$ or $k_{f}$ using the following equation:

$$
A R_{f}^{2}=k_{f} \frac{e_{0}+1}{e_{0}}=\frac{k_{c}}{\alpha} \frac{e_{0}+1}{e_{0}} .
$$

The dry density variation with the mixing ratio can also be calculated based on the derived porosity. The void ratio is a piecewise function depending on the mixing ratio, and it is expressed as

$$
\begin{aligned}
& e_{\text {mix }}=\frac{n_{\text {mix }}}{1-n_{\text {mix }}}=e_{0}(1-x) \quad \text { if } x<x_{\mathrm{cr}}, \\
& e_{\text {mix }}=\left(e_{0}+1\right) x-1 \quad \text { if } x \geq x_{\mathrm{cr}} .
\end{aligned}
$$

Using the derived void ratio equations, the dry density can be expressed as

$$
\gamma_{d}=\frac{G_{s} \gamma_{w}}{\left(1+e_{\mathrm{mix}}\right)} .
$$

Figures 2(a)-2(c) present the variation of the void ratio, the dry density, and the computed hydraulic conductivity, respectively. The void ratio of the mixture has a V-shaped curve with the minimum at the critical mixing ratio. The dry density increases with the mixing ratio and then starts decreasing at the critical mixing ratio. Until reaching the 


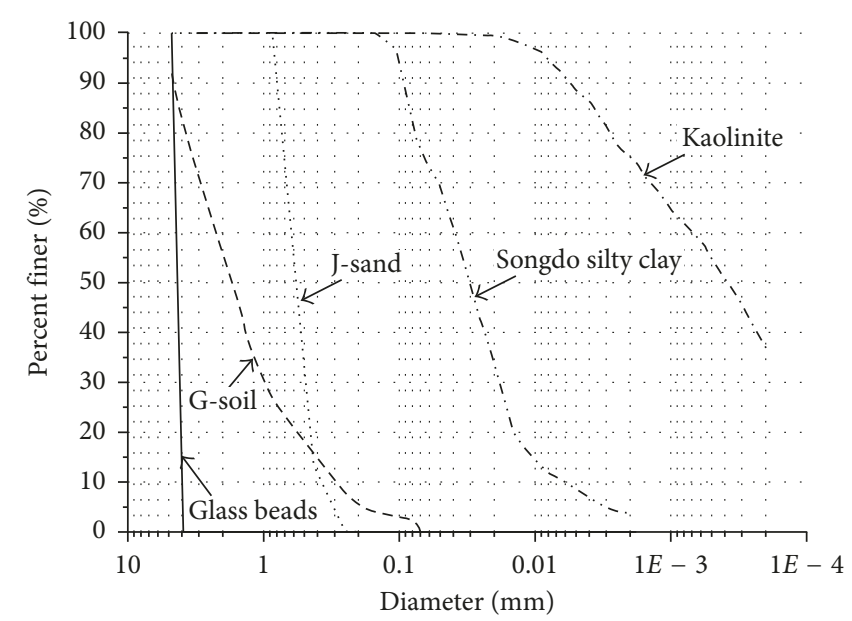

FIgure 3: Particle size distribution curves.

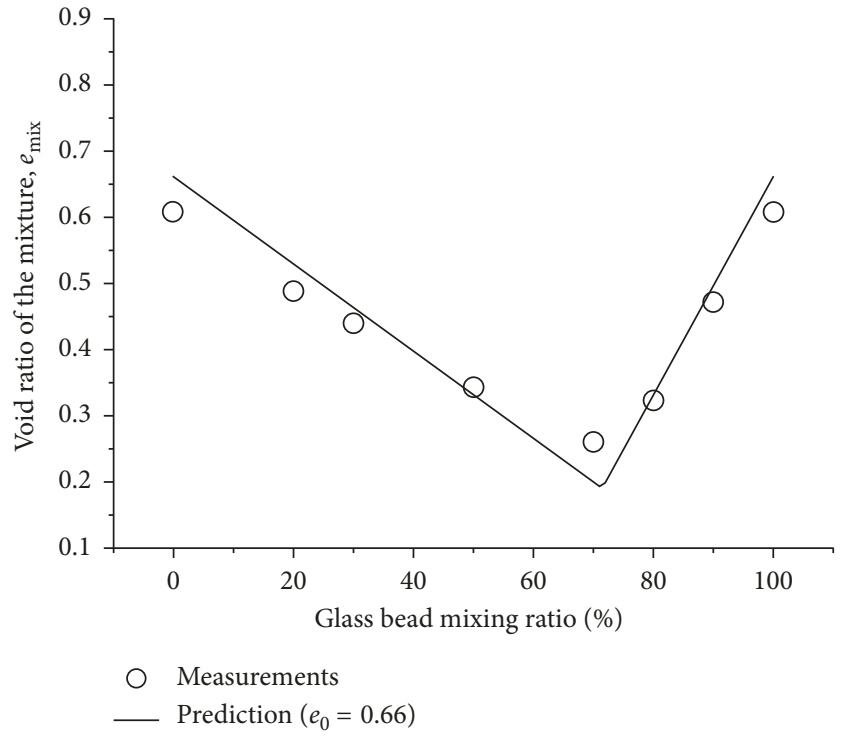

(a)

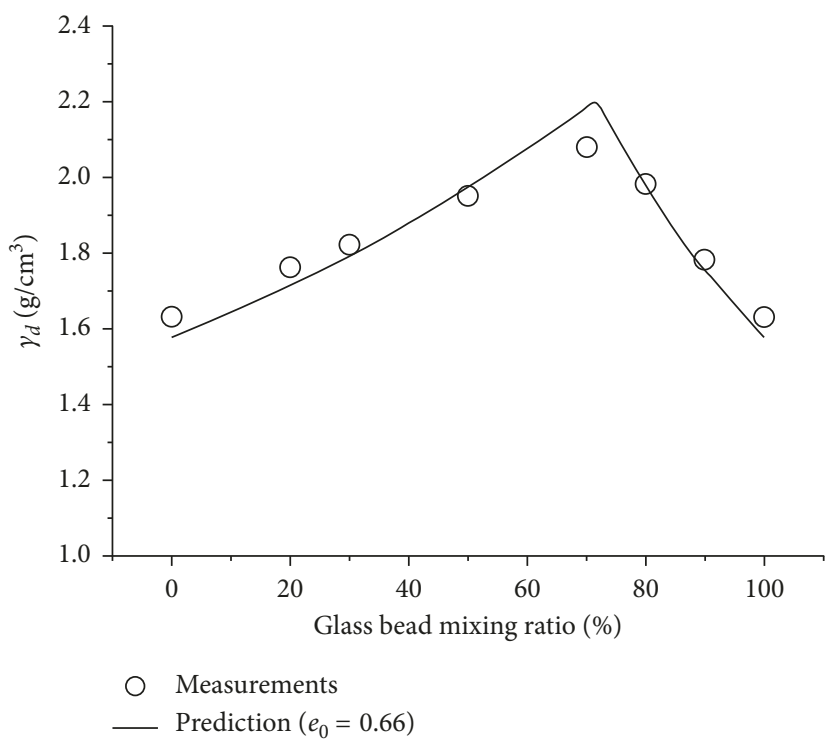

(b)

Figure 4: Prediction and measurement comparison of the glass bead and J-sand mixture: (a) void ratio and (b) dry density.

critical mixing ratio, the hydraulic conductivity slightly decreases with the increasing mixing ratio which is then drastically increased to $k_{c}$. This model response has significant implication that the coarse-fine soil mixture with the critical mixing ratio shows more impervious response than the pure fine soil. To verify these responses of the model, experiments were conducted.

\section{Evaluation of the Model against Experiment Data}

3.1. Experiments. To verify the model, comparison between the predicted values from the introduced model herein and the measurements is made. The materials to make the soil mixture are glass beads, Joomunjin standard sand (J-sand), kaolinite, Gwanak granite soil (G-soil), and Songdo silty
Clay (S-soil). Figure 3 presents the particle size distribution curves of each soil. With those soils, three mixtures were made. The first experiments were conducted on the mixture of glass beads and J-sand, the quality-controlled materials. Accordingly, the particle sizes of these materials were very uniform as shown in Figure 3, so unintended particle sizes were not possibly included in the mixture. The mixture of J-sand and kaolinite was employed to evaluate the hydraulic conductivity variation of soils, not including the manufactured product. As shown in Figure 3, the particle size of kaolinite is not as uniform as that of J-sand. Consequently, the particle sizes of this mixture are slightly more various than that of the mixture of glass beads and J-sand. The natural soils, G-soil and S-soil, were obtained from Gwanak Mountain in Seoul and Songdo in Incheon, respectively. Due to the inherent variability of the natural soil, each soil 


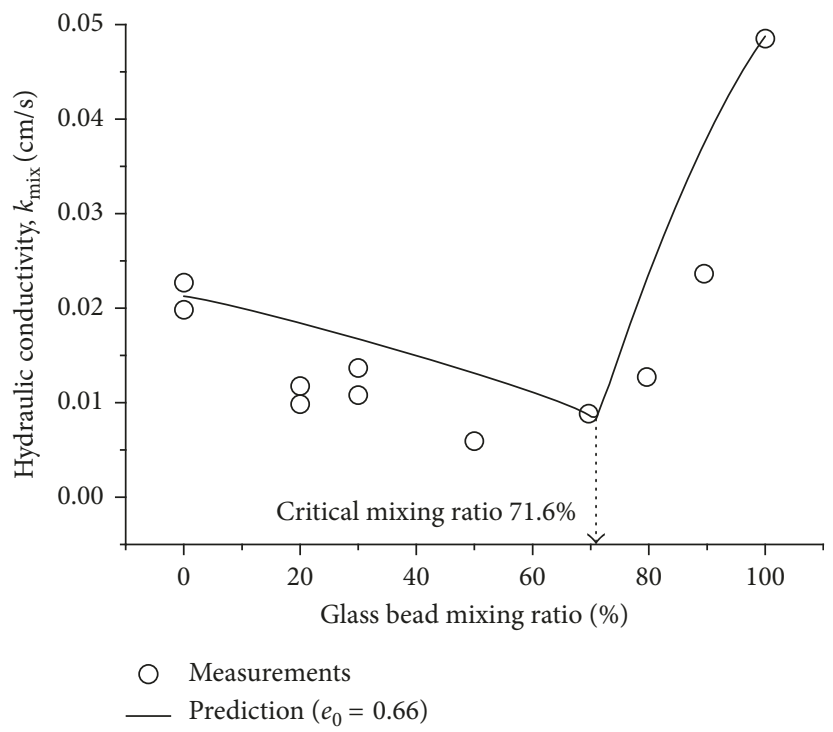

FIGURE 5: Hydraulic conductivity evolution of the glass bead and J-sand mixture with the mixing ratio.

TABLE 1: Properties of soils and glass beads for the mixture.

\begin{tabular}{|c|c|c|c|c|c|c|c|c|c|c|}
\hline Soil & $G_{s}$ & $\mathrm{PL}$ & $\mathrm{LL}$ & PI & $D_{10}(\mathrm{~mm})$ & $D_{30}(\mathrm{~mm})$ & $D_{60}(\mathrm{~mm})$ & $C_{u}$ & $C_{c}$ & USCS \\
\hline Kaolinite & 2.63 & 30 & 58 & 28 & - & - & - & - & - & $\mathrm{CL}$ \\
\hline Songdo silty clay & 2.67 & 25 & 35 & 10 & 0.061 & 0.018 & 0.038 & 0.62 & 0.14 & ML \\
\hline Gwanak granite soil & 2.59 & - & - & - & 0.21 & 2.1 & 4.3 & 10 & 0.42 & $\mathrm{SP}$ \\
\hline Joomunjin sand & 2.64 & - & - & - & 0.385 & 0.47 & 0.6 & 1.55 & 0.95 & $\mathrm{SP}$ \\
\hline Glass beads & 2.60 & \multicolumn{9}{|c|}{ Sphere (4 mm diameter) } \\
\hline
\end{tabular}

contains various particle sizes although their dominant particle sizes are greatly different. With this natural soil mixture, the applicability of the introduced model to the natural soil is checked.

Three combinations of coarse and fine soils were mixed with the various coarse soil mixing ratios and were compacted with optimized moisture content (OMC). Thereafter, the hydraulic conductivity tests were conducted. For the mixture of glass beads and J-sand, constant head permeability tests were performed with the specimen whose diameter and height were $10 \mathrm{~cm}$ and $12.8 \mathrm{~cm}$, respectively. The hydraulic head was $60 \mathrm{~cm}$. The variable head permeability tests were conducted on the J-sand and kaolinite mixture and the G-soil and S-soil mixture. The diameter and the height of the specimens were $6.2 \mathrm{~cm}$ and $7 \mathrm{~cm}$, respectively.

3.2. Glass Bead and J-Sand Mixture. Glass beads and J-sand were used to evaluate the hydraulic conductivity of the mixture. In this case, glass beads and J-sand represent the coarse and fine soils, respectively. The mixture was compacted, and constant head permeability tests were conducted with the various glass bead mixing ratios of $0 \%, 20 \%, 30 \%$, $50 \%, 70 \%, 80 \%, 90 \%$, and $100 \%$. Note that the model was derived assuming that the void ratios of each pure soil are the same, and their average value was employed as a parameter.
In this experiment, 0.72 was the average of $e_{c}$ and $e_{f}$, and it showed very good agreement with a series of measurement data as shown in Figure 4(a). The average specific gravity of J-sand and glass beads, 2.62, was used for the computation. The difference between the specific gravities of the two is small, so the possible error caused by this is neglected. As shown in Figure 4(b), the measured dry density follows the trend of the measurements.

Figure 5 shows the hydraulic conductivity variation with the glass bead mixing ratio. Both the computed and the measured hydraulic conductivities of the mixture strongly depend on the mixing ratio. The value of $k_{\text {mix }}$ slightly decreases with the increasing mixing ratio until the critical ratio; thereafter, $k_{\text {mix }}$ is drastically increased to the value of $k_{c}$. Considering the unintended size particles that are possibly contained in J-sand, the prediction from the introduced model well describes the measured values.

3.3. J-Sand and Kaolinite Mixture. The soil mixture of J-sand and kaolinite was used for the introduced model verification. In this case, J-sand represents the coarse soil. As listed in Table 1 , the $G_{s}$ values of the two soils are practically identical. Hence, the difference is neglected, and the value of 2.64 is employed for the computation. The mixture was compacted, and variable head permeability tests were conducted with the 


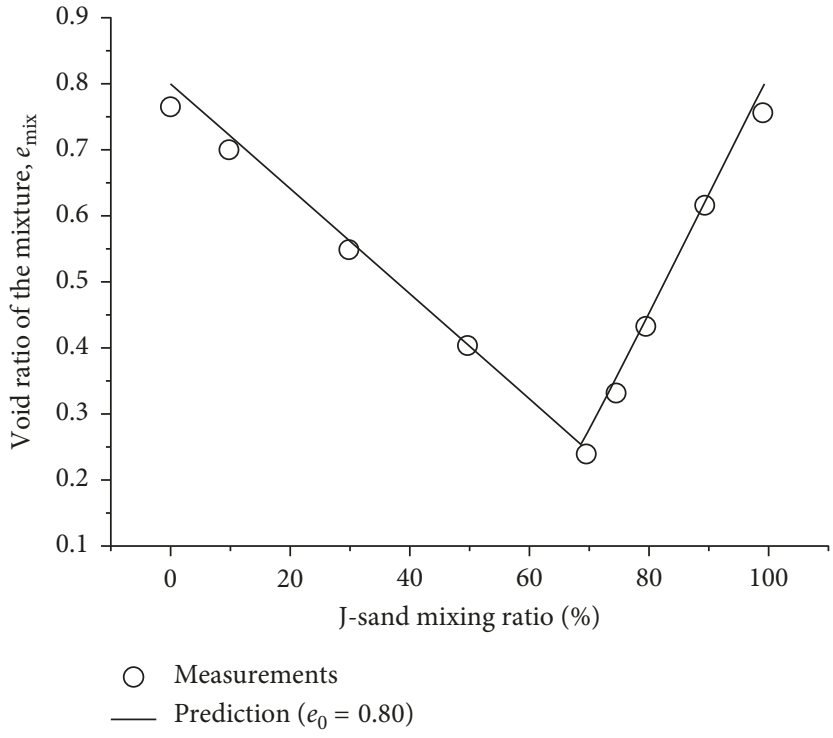

(a)

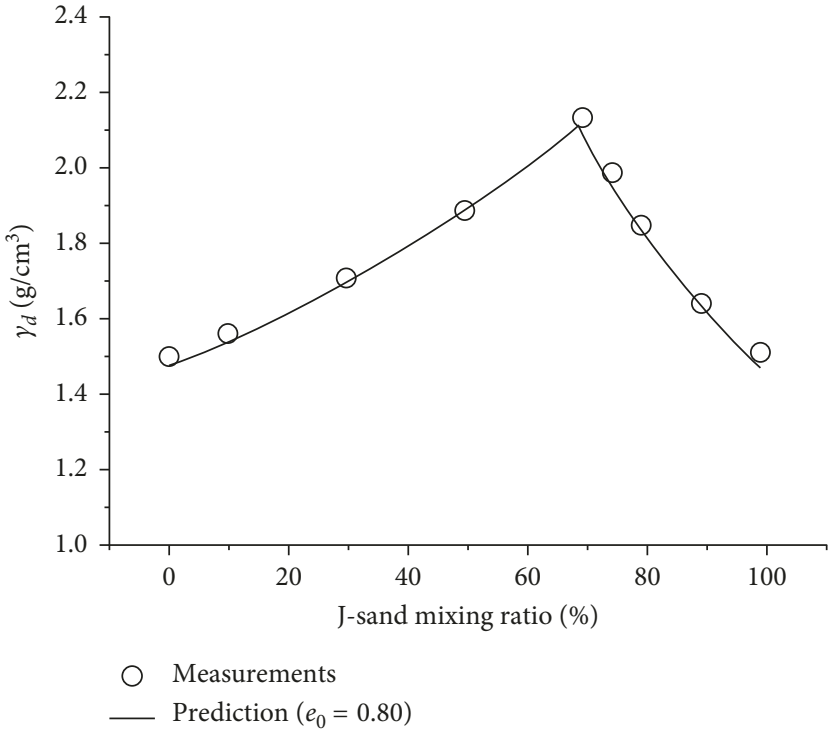

(b)

Figure 6: Prediction and measurement comparison of the J-sand and kaolinite mixture: (a) void ratio and (b) dry density.

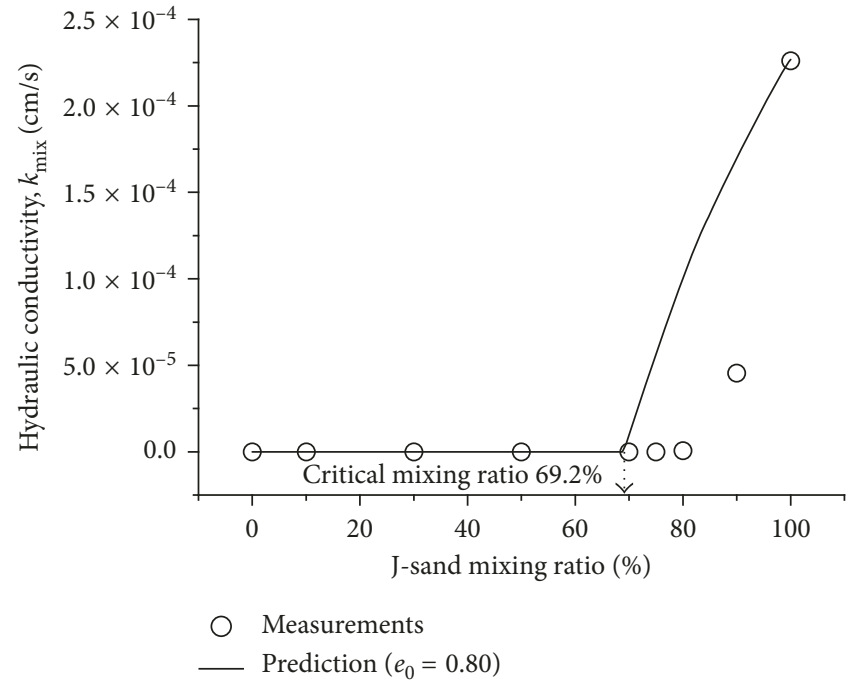

(a)

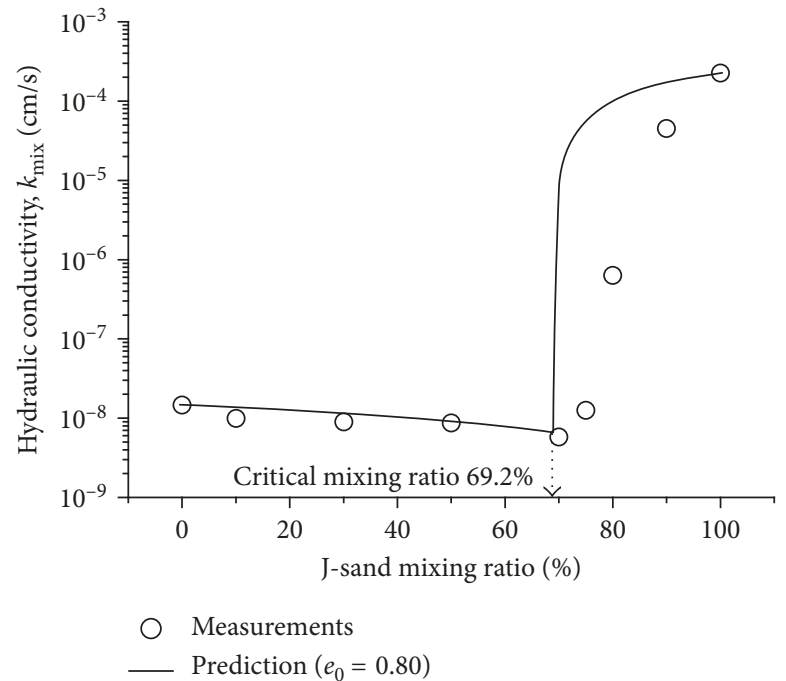

(b)

Figure 7: Prediction and measurement comparison of the J-sand and kaolinite mixture: (a) hydraulic conductivity and (b) hydraulic conductivity in semilog scale.

various J-sand mixing ratios of $0 \%, 10 \%, 30 \%, 50 \%, 70 \%$, $75 \%, 80 \%, 90 \%$, and $100 \%$.

Figures 6(a) and 6(b) compare the measured and predicted values of the void ratio and dry density, respectively. As previously noted, the model is derived assuming that the respective void ratios of the pure coarse and fine soils are the same, and the average void ratio of the two soil is used as a parameter. In this prediction, the average void ratio of 0.72 was used. As shown in Figures 6(a) and 6(b), the prediction curves show very good agreement with the measurements. The introduced prediction equation decently describes the measurement data considering the inherent variability of the soils.
Figure 7 (a) shows the hydraulic conductivity variation of the soil mixture. Both the computed and measured hydraulic conductivities of the soil mixture strongly depend on the mixing ratio. To clearly see the $k_{\text {mix }}$ variation, semilog plot is presented in Figure $7(\mathrm{~b})$. The value of $k_{\text {mix }}$ slightly decreases with the increasing mixing ratio until the critical ratio; thereafter, $k_{\text {mix }}$ is dramatically increased to the value of $k_{c}$. In this case, the computed critical mixing ratio was $70.5 \%$. As shown in the figure, the values computed from the introduced model have a good agreement with the measurements until the critical mixing ratio; thereafter, the model overestimates but follows the trend of 


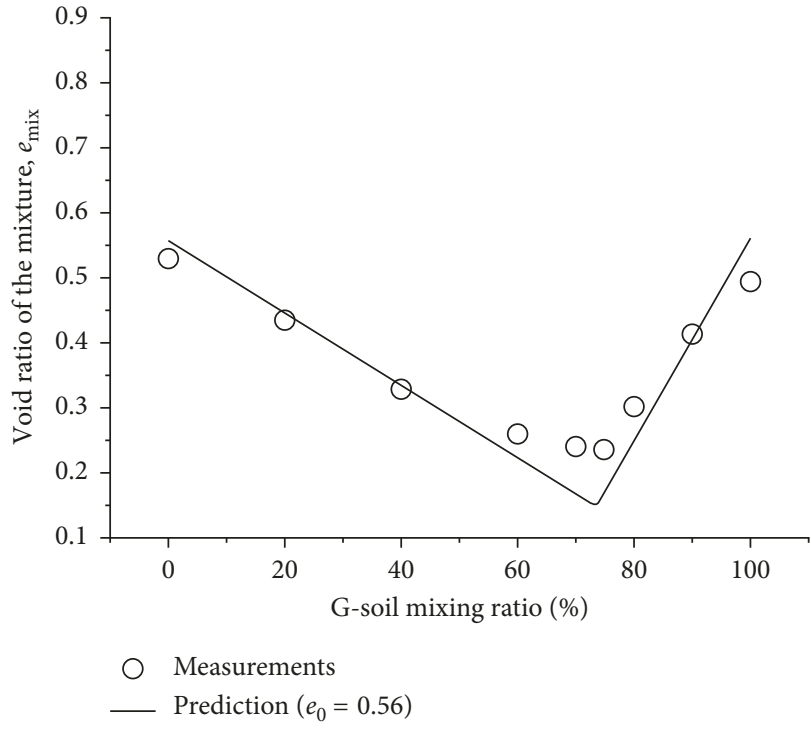

(a)

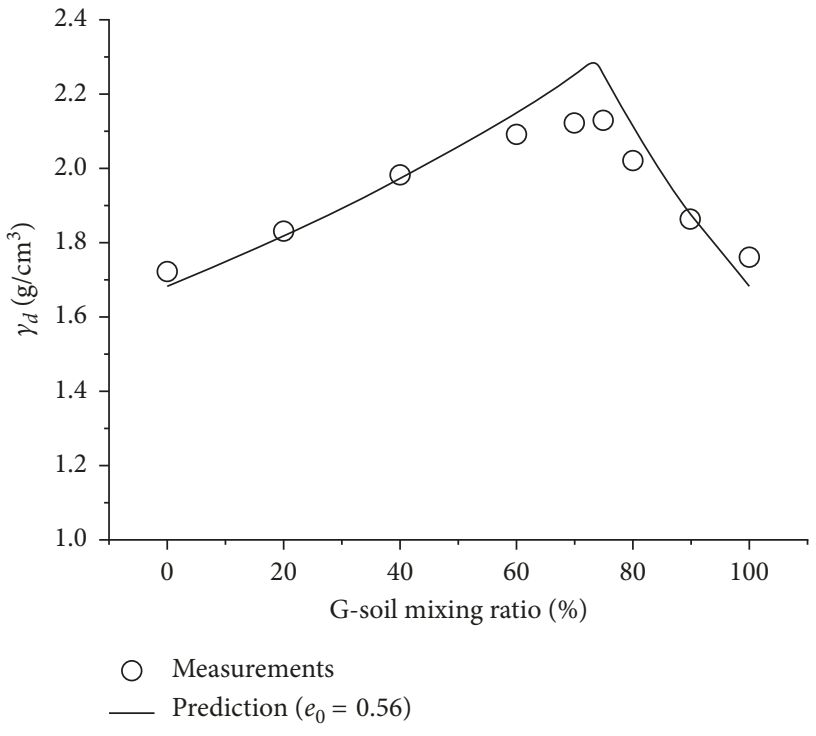

(b)

Figure 8: Prediction and measurement comparison of the G-soil and S-soil mixture: (a) void ratio and (b) dry density.

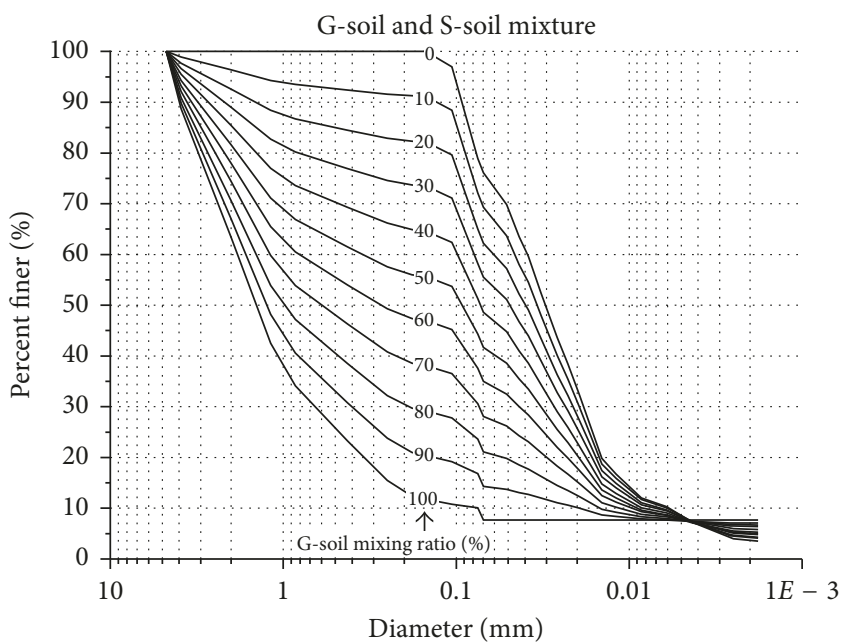

FIGURE 9: Particle distribution curves for the G-soil and S-soil mixture.

the measurements. Overall, the model decently describes $k_{\text {mix }}$ of the J-sand and kaolinite mixture.

3.4. G-Soil and S-Soil Mixture. The previous two experiments for the model verification were conducted with the glass beads and the quality-controlled soils, so they have relatively less variability than for natural soil samples. To check the applicability of the introduced model to natural soils, the experiments were conducted with the natural soil samples of Gwanak granite soil (G-soil) and Songdo silty clay (S-soil). Comparison with the existing empirical model suggested by Hazen [1] is also made. Based on the index properties, the G-soil and S-soil are classified as SP and ML by the Unified Soil Classification System (USCS), respectively. G-soil is regarded as the coarse soil in this verification.
The mixture of G-soil and S-soil was maximally compacted, and variable head permeability tests were conducted with the various G-soil mixing ratios of $0 \%, 20 \%, 40 \%, 60 \%, 70 \%, 75 \%$, $90 \%$, and $100 \%$.

Figure 8(a) shows the void ratio prediction curves based on the introduced model and the measurements. In this verification experiment, the average void ratio of the two soils, 0.56 , is used. The dry density prediction curve shown in Figure 8(b) well describes the trend of the test results although the natural soil mixture contains more widely distributed particle sizes, as shown in Figure 3.

Figure 9 presents the computed particle size distribution curve of the G-soil and S-soil mixture based on that of each soil. The G-soil mixing ratio is noted on each curve. From these curves, the $D_{10}$ value, the grain size diameter at which $10 \%$ by weight of the soil particles are finer, is 


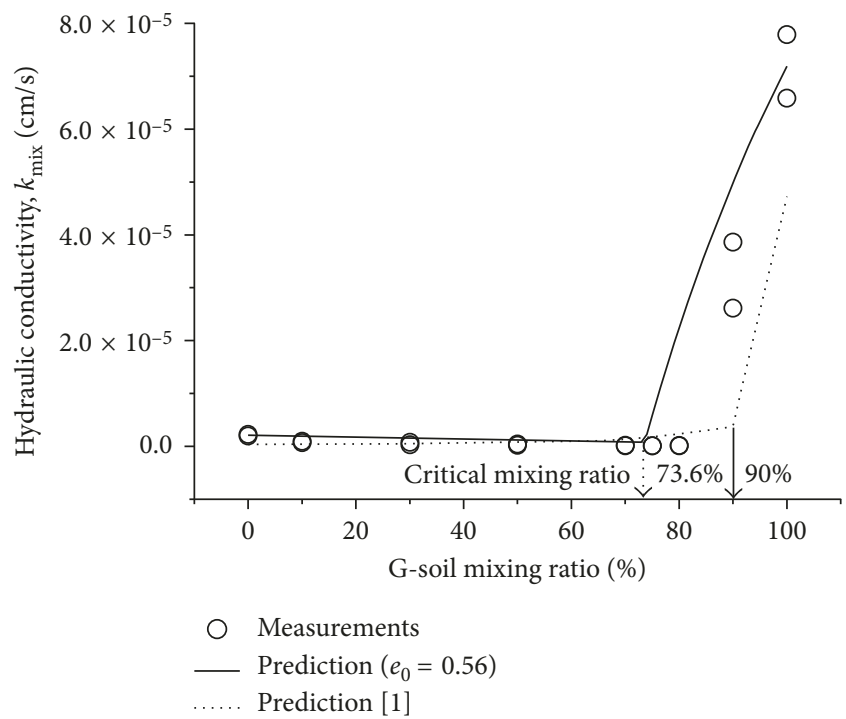

(a)

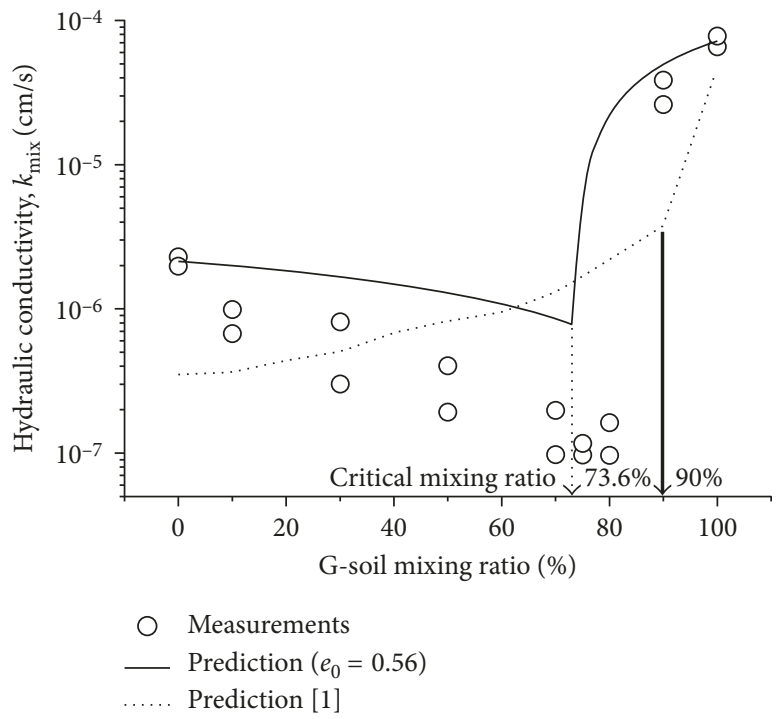

(b)

Figure 10: Prediction and measurement comparison of the G-soil and S-soil mixture: (a) hydraulic conductivity and (b) hydraulic conductivity in semilog scale.

evaluated, and the hydraulic conductivity is computed with the suggested equation by Hazen [6]:

$$
k=C D_{10}^{2} .
$$

For $k$ in $\mathrm{cm} / \mathrm{s}$ and $D_{10}$ in $\mathrm{mm}$, the coefficient $C$ in (30) is equal to 1.0.

Figure 10(a) presents the hydraulic conductivities of the soil mixture that strongly depend on the mixing ratio are the same as those of the other two soil mixtures. The predicted $k_{\text {mix }}$ with the introduced model in this study slightly decreases with the increasing G-soil mixing ratio until the critical mixing ratio and then drastically increases. This prediction follows the trend of the measurements. The predicted $k_{\text {mix }}$ with the suggested equation by Hazen [1] slightly increases until $90 \%$ of the G-soil mixing ratio and then drastically increases. Note that the Hazen equation is solely a function of $D_{10}$, and this increases with the coarse soil mixing ratio. Hence, it cannot describe the decreasing response of the measurements.

To clearly see the $k_{\text {mix }}$ variation, semilog plot is presented in Figure 10(b). As shown in the figure, the prediction by the introduced model slightly overestimates the measured hydraulic conductivities. The measured $k_{\text {mix }}$ is decreased up to approximately $80 \%$ of the G-soil mixing ratio, but the computed critical mixing ratio is $73.6 \%$. Presumably, the soil particles with various sizes inevitably contained in the natural soil mixture reduced the water conveyance area, so this caused the difference between the prediction with the introduced model and measurements. For the empirical model suggested by Hazen [1], it is clearly found that the predicted $k_{\text {mix }}$ cannot describe the decreasing response of the measurement before the critical mixing ratio.

Both the predicted values by the introduced model and the experiment results show that the hydraulic conductivity of the coarse-fine soil mixture with the critical mixing ratio is lower than that of the pure fine soil. Therefore, in case of designing and constructing the core of the earth dam, blankets or liners of the landfill, the coarse-fine mixture with the critical mixing ratio would form better seepage barriers against fluids than the pure fine soil. As one can expect, this mixture has the better constructability than the pure fine soil, as well.

\section{Conclusions}

To analyze the hydraulic conductivity variation of the coarse and fine soil mixture, a new model that takes into account two distinct particle size distributions was introduced. The porosity, the dry density, and the hydraulic conductivity of the soil mixture were theoretically estimated with respect to the mixing ratio. The new model is developed based on this porosity and needs the respective hydraulic conductivities of coarse and fine soils as the parameters. To verify the model, laboratory-scale permeability tests were conducted, and the results showed that the introduced model in this paper successfully describes the hydraulic conductivity variation of the soil mixture.

Both the predicted values by the introduced model and the experiment results show that the hydraulic conductivity of the coarse-fine soil mixture strongly depends on the mixing ratio. It is slightly decreased with the increasing mixing ratio until the critical mixing ratio, and thereafter, it is drastically increased. At the critical mixing ratio, the coarse-fine mixture has the lowest hydraulic conductivity.

Based on the introduced model response and the observations, it can be inferred that the coarse-fine soil mixture with the critical mixing ratio is more effective than solely employing the fine soil when designing and constructing the impervious layers such as the core of the earth dam, blankets or liners of the landfill. However, the proper soil size for these practical usages has not been studied herein. 


\section{Conflicts of Interest}

The authors declare that they have no conflicts of interest.

\section{Acknowledgments}

This work was supported by the National Research Foundation of Korea (NRF) grant funded by the Korea government (MSIP) (no. 2015R1A2A1A01007980).

\section{References}

[1] A. Hazen, "Discussion of "dams on sand foundations"," Transactions of the American Society of Civil Engineers, vol. 73, pp. 199-203, 1911.

[2] J. Kozeny, "Uber kapillare Leitung des Wassers in Boden," Akademie der Wissenschaften in Wien, vol. 2a, no. 136, pp. 271-306, 1927, in German.

[3] P. C. Carman, "Fluid flow through granular beds," Transactions of the Institution of Chemical Engineers, vol. 15, pp. 150-166, 1937.

[4] P. C. Carman, "Permeability of saturated sands, soils and clays," Journal of Agricultural Science, vol. 29, pp. 263-273, 1939.

[5] D. M. Burmister, "Principles of permeability testing of soils," in Symposium on Permeability of Soils, ASTM Special Technical Publication, West Conshohocken, PA, USA, 1954.

[6] T. W. Lambe, "The permeability of compacted fine-grained soils," in Symposium on Permeability of Soils, ASTM Special Technical Publication, West Conshohocken, PA, USA, 1954.

[7] R. E. Olson, "Effective stress theory of soil compaction," Journal of the Soil Mechanics and Foundation Division, vol. 89, no. SM2, pp. 27-45, 1963.

[8] J. K. Mitchell, D. R. Hopper, and R. C. Campanella, "Permeability of compacted clay," Journal of the Soil Mechanics and Foundation Division, vol. 91, no. SM4, pp. 41-65, 1965.

[9] M. E. Horn, "Estimating soil permeability rates," Journal of the Irrigation and Drainage Division, vol. 97, no. IR2, pp. 263274, 1971.

[10] I. Garcia-Bengochea, C. W. Lovell, and A. G. Altschaeffl, "Pore distribution and permeability of silty clays," Journal of the Geotechnical Engineering Division, vol. 105, no. GT7, pp. 839-856, 1979.

[11] V. L. Hauser, "Seepage control by particle size selection," Transactions of the American Society of Civil Engineers, vol. 21, no. 4, pp. 691-695, 1978.

[12] M. C. Wang and C. C. Huang, "Soil compaction and permeability prediction models," Journal of Environmental Engineering, vol. 110, no. 6, pp. 1063-1083, 1984.

[13] R. P. Chapuis and M. Aubertin, "On the use of the KozenyCarman equation to predict the hydraulic conductivity of soils," Canadian Geotechnical Journal, vol. 40, pp. 616-628, 2003.

[14] R. A. Freeze and J. A. Cherry, Groundwater, Prentice-Hall, Englewoods Cliffs, NJ, USA, 1979.

[15] F. A. L. Dullien, "Prediction of tortuosity factors from pore structure data," AIChE Journal, vol. 21, no. 4, pp. 820-822, 1975.

[16] P. Guo, "Dependency of tortuosity and permeability of porous media and directional distribution of pore voids," Transport in Porous Media, vol. 95, no. 2, pp. 285-303, 2012.

[17] A. Koponen, M. Kataja, and J. Timonen, "Tortuous flow in porous media," Physical Review E, vol. 54, no. 1, pp. 406-410, 1996.
[18] M. Mota, J. A. Teixeira, and A. Yelshin, "Binary spherical particle mixed beds porosity and permeability relationship measurement," Transactions of the Filtration Society, vol. 1, no. 4, pp. 101-106, 2001.

[19] R. Dias, J. A. Teixeira, M. Mota, and A. Yelshin, "Tortuosity variation in a low density binary particulate bed," Seperation and Purification Technology, vol. 51, no. 2, pp. 180-184, 2006.

[20] J. Comiti and M. Renaud, "A new model for determining mean structure parameters of fixed beds from pressure drop measurements: application to beds packed with parallelepipedal particles," Chemical Engineering Science, vol. 44, no. 7, pp. 1539-1545, 1989.

[21] H. Weissberg, "Effective diffusion coefficients in porous media," Journal of Applied Physics, vol. 34, no. 9, pp. 26362639, 1963.

[22] A. Duda, Z. Koza, and M. Matyka, "Hydraulic tortuosity in arbitrary porous media flow," Physical Review E, vol. 84, no. 3, p. 036319, 2011.

[23] W. C. Krumbein and G. D. Monk, "Permeability as a function of the size parameters of unconsolidated sand," Transactions of the AIME, vol. 151, no. 1, pp. 153-163, 1942.

[24] R. R. Berg, "Method for determining permeability from reservoir rock properties," Transactions of the Gulf Coast Association of Geological Societies, vol. 20, pp. 303-317, 1970.

[25] M. S. Alyamani and Z. Sen, "Determination of hydraulic conductivity from grain-size distribution curves," Ground Water, vol. 31, pp. 551-555, 1993.

[26] C. Y. Chen, A. G. R. Bullen, and H. A. Elnaggar, Permeability and Related Principles of Coal Refuse, Transportation Research Record, 640, pp. 49-52, 1977.

[27] F. K. Boadu, "Hydraulic conductivity of soils from grain-size distribution: new models," Transactions of the Gulf Coast Association of Geological Societies, vol. 20, pp. 303-317, 2000.

[28] K. Terzaghi, R. B. Peck, and G. Mesri, Soil Mechanics in Engineering Practice, John Wiley \& Sons, Inc., New York, NY, USA, 1996.

[29] R. J. Fragaszy, W. Su, and F. H. Siddiqi, "Effects of oversize particles on the density of clean granular soils," Geotechnical Testing Journal, vol. 13, no. 2, pp. 106-114, 1990.

[30] A. Shakoor and B. Cook, "The effect of stone content, size, and shape on the engineering properties of a compacted silty clay," Bulletin of Association of Engineering Geologists, vol. 27, no. 2, pp. 245-253, 1990.

[31] D. Marion, "Acoustical, mechanical, and transport properties of sediments and granular materials," Ph.D. dissertation, Stanford University, Stanford, CA, USA, 1990.

[32] T. L. Shelley and D. E. Daniel, "Effect of gravel on hydraulic conductivity of compacted soil liners," Journal of Geotechnical Engineering, vol. 119, no. 1, pp. 54-68, 1993.

[33] C. E. Koltermann and S. M. Gorelick, "Fractional packing model for hydraulic conductivity derived from sediment mixture," Water Resources Research, vol. 31, no. 12, pp. 3283-3297, 1995.

[34] P. J. Kamann, R. W. Ritzi, D. F. Dominic, and C. M. Conrad, "Porosity and permeability in sediment mixtures," Ground Water, vol. 45, no. 4, pp. 429-438, 2007.

[35] J. K. Mitchell and K. Soga, Fundamentals of Soil Behavior, John Wiley \& Sons, Inc., Hoboken, NJ, USA, 3rd edition, 2005. 


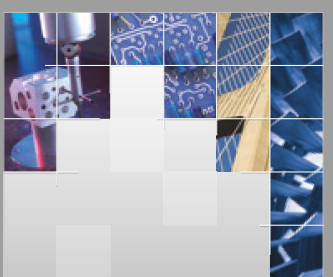

\section{Enfincering}
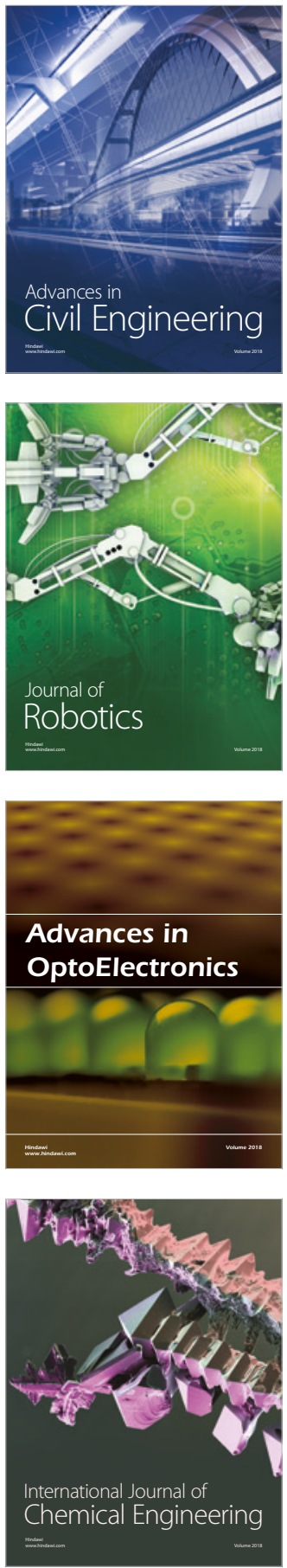

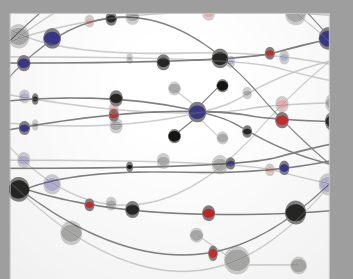

\section{Rotating \\ Machinery}

The Scientific World Journal

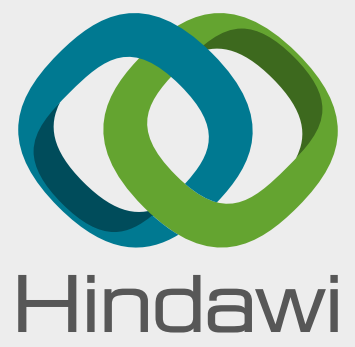

Submit your manuscripts at

www.hindawi.com
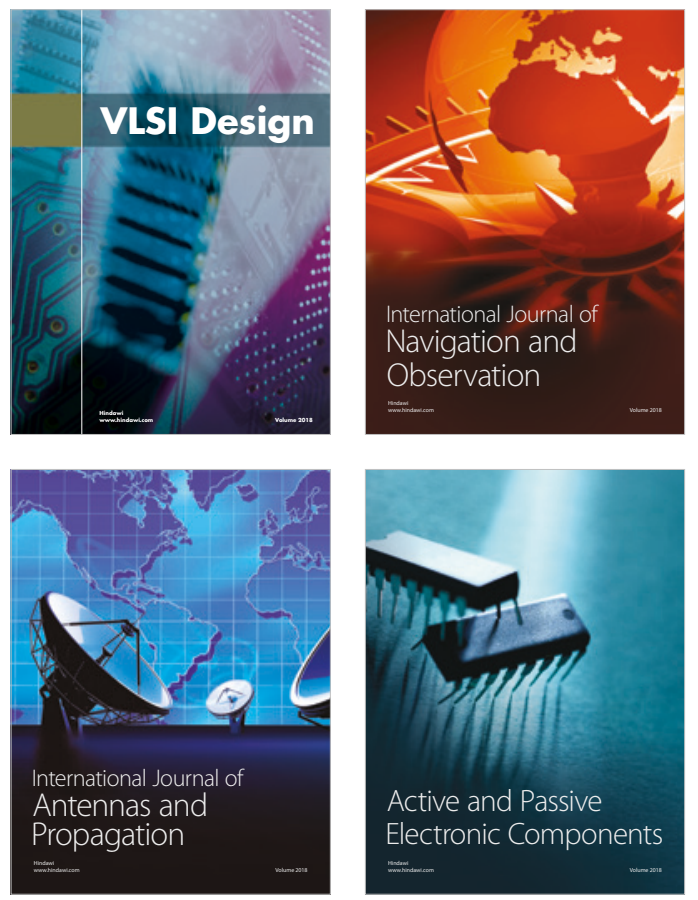
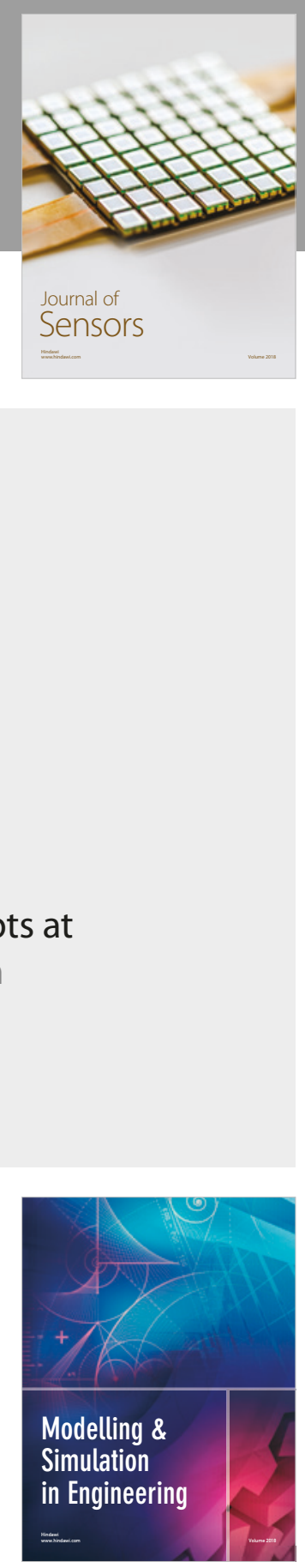

\section{Advances \\ Multimedia}
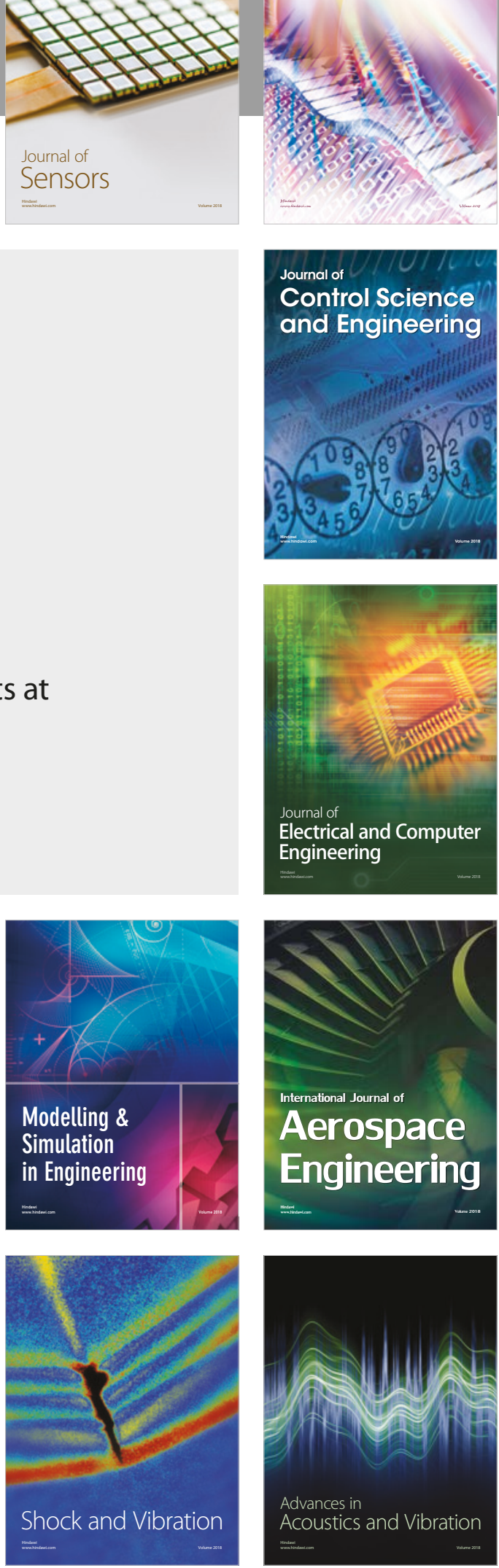